\title{
Combination of polydextrose and lactitol affects microbial ecosystem and immune responses in rat gastrointestinal tract
}

\author{
Seppo Peuranen*, Kirsti Tiihonen, Juha Apajalahti, Anu Kettunen, Markku Saarinen and \\ Nina Rautonen \\ Danisco Innovation, Enteromix Research, Sokeritehtaantie 20, FIN-02460 Kantvik, Finland
}

(Received 18 September 2003 - Revised 26 January 2004 - Accepted 30 January 2004)

\begin{abstract}
The effects of various dietary fibres on gut health have been studied extensively but their combined effects are scarcely documented. In the present study the effects of $2 \%(\mathrm{w} / \mathrm{w})$ polydextrose (PDX), $2 \%(\mathrm{w} / \mathrm{w})$ disaccharide lactitol, or $2 \%(\mathrm{w} / \mathrm{w})$ PDX+2 $\%(\mathrm{w} / \mathrm{w})$ lactitol on gut microflora, microbial metabolism and gut immune responses were investigated in rats. Both PDX and lactitol alone had an effect on many of the studied parameters, but their combination had stronger than additive effects in some parameters. The PDX+lactitol combination altered the microbial community structure as seen by a culture-independent method, percentage guanine + cytosine $(\% \mathrm{G}+\mathrm{C})$ profiling, increasing the areas of $\% \mathrm{G}+\mathrm{C} 35-39(P<0.0001)$ and $\% \mathrm{G}+\mathrm{C} 45-49(P=0.0002)$, and decreasing $\% \mathrm{G}+\mathrm{C} 65-74(P<0.0003)$. These changes were also reflected in the microbial metabolism so that the production of biogenic amines and branched volatile fatty acids was significantly reduced, by $12(P=0.03)$ and $50 \%(P=0.002)$, respectively, indicating a shift from putrefactive towards saccharolytic metabolism. PDX increased the secretion of IgA in the caecum $(P=0 \cdot 007)$. Secretion of IgA increased even more, almost ten-fold, with the combination of PDX+lactitol $(P<0.0001)$ when compared with the control group. Lactitol increased the production of butyrate by caecal microbes by two- to three-fold when compared with the PDX or control group $(P<0 \cdot 0001)$. Butyrate is a preferred energy source for mucosal cells; thus a boost in the availability of energy for immune cells may have still added to the synergistic effects of PDX and lactitol on immune cells. It is noteworthy that improvement in the IgA secretion occurred without signs of mucosal inflammation.
\end{abstract}

Polydextrose: Lactitol: Microbial metabolism: Immunoglobulin A

Polydextrose (PDX) is a randomly bonded glucose polymer and, depending on its purity, contains residual sorbitol $(6 \%)$ but no free glucose. It has a low energy value $(4 \cdot 2 \mathrm{~kJ} / \mathrm{g})$, and it appears to fit into the physiological definition of dietary fibre (for recent discussions on the definitions, see Hara et al. 2000; Craig et al. 2001). PDX is used as a bulking agent, and as a sugar or fat replacer in the food industry. Earlier studies have shown that PDX improves bowel movement and increases residual SCFA levels in human subjects (Jie et al. 2000). The laxative threshold of PDX in man is as high as $90 \mathrm{~g} / \mathrm{d}$ (Pfizer, 1978).

Lactitol is a sugar alcohol made industrially by lactose hydrogenation. It is used as a low-energy sweetener $(9.7 \mathrm{~kJ} / \mathrm{g})$ and is a suitable dietary component for diabetic patients (Natah et al. 1997). Being a non-absorbable sugar alcohol (Patil et al. 1987), it increases the water content of the intestine and reduces transit time (Lee \& Storey, 1999; Soontornchai et al. 2003). Lactitol has been shown to reduce $\mathrm{NH}_{3}$ and amine levels in the digesta (Piva et al. 1996). The proposed mechanism for this is a reduced residence time of the intestinal contents, which reduces the time for $\mathrm{NH}_{3}$ generation and acidifies the intestinal lumen (Watanabe et al. 1995; Masini et al. 1999).
The effects of combinations of different $\mathrm{C}$ sources on colon function and its microbial metabolism are not extensively studied. The combination of $7 \%$ readily fermenting gum arabic and $7 \%$ non-fermenting cellulose changed the caecal fermentation pattern in rats in comparison with those at $14 \%$ concentrations alone (Topping et al. 1985). Combining $3 \%$ PDX with either pectin or cellulose increased the water-holding capacity of faeces and faecal weight in rats (Oku et al. 1991). Solomons \& Rosenthal (1985), based on residual $\mathrm{H}_{2}$ in breath, found that PDX in combination with foods was more readily fermented than alone. Livesey et al. (1993) observed that PDX in combination with lactitol increased breath $\mathrm{H}_{2}$ production more than could be anticipated from their $\mathrm{H}_{2}$ production separately. Govers et al. (1999) studied the effect of slowly fermenting insoluble NSP on the fermentation of rapidly fermenting resistant starch in different intestinal sections of pigs. According to the authors, by increasing the bulk of digesta, NSP (wheat bran) speeded up the transit time of digesta, which then pushed resistant starch to be fermented into the distal colon producing SCFA.

In the present study we examined the effects of PDX (Litesse Ultra), lactitol and their combination on rats, concentrating on the gut microflora, microbial metabolites and 
immunological responses. A percentage guanine + cytosine $(\% \mathrm{G}+\mathrm{C})$ profiling method, independent of the culturability of microbes, was applied in the present study to examine diet-related changes in the gut microbial community (Apajalahti et al. 2001). In addition to changes in the microflora composition, we also measured indicators of microbial metabolism such as pH, SCFA and biogenic amines. Several indicators of the gut immune system were also included in the present study. Pro-inflammatory cytokines (IL-1 and TNF- $\alpha$ ) and a non-inflammatory cytokine (transforming growth factor (TGF)- $\beta$ ) produced by the intestinal immune and/or epithelial cells, and the crypt:villus measurement from histological samples reflect the immunological status of the gut mucosa (Olson et al. 1993; Letterio \& Roberts, 1998). The measurement of IgA in the digesta characterises resistance against pathogens via neutralising antibodies that prevent adhesion on the epithelium, and tolerance against dietary components (Smith et al. 2000). A well-balanced regulation of immune responses in the intestinal environment has been proposed to be characterised by high IgA levels (for example, Kelsall \& Strober, 1999).

\section{Materials and methods}

\section{Animals and experimental design}

Male Wistar rats (4 weeks old) were obtained from the Biocentre of the University of Helsinki and housed in a Scantainer cabinet with controlled temperature $\left(27 \pm 2^{\circ} \mathrm{C}\right)$ and a $12 \mathrm{~h}$ light $-12 \mathrm{~h}$ dark cycle. The animals had free access to food and water.

Forty-eight rats were divided into four feeding treatments; three animals per cage. The rats started to feed on the experimental diet on the day they arrived at the age of 4 weeks (weight 85.3 (SE 1.9) g). Before that, they were given rat feed in their nursery. The experiment lasted 3 weeks. The animals were weighed once weekly. The feeding groups were: control diet without non-digestible fibre (see later); PDX (2\%, w/w); lactitol $(2 \%, \mathrm{w} / \mathrm{w})$; PDX $(2 \%, \mathrm{w} / \mathrm{w})+$ lactitol $(2 \%, \mathrm{w} / \mathrm{w})$.

At the end of the intervention period, the rats were anaesthetised with $\mathrm{CO}_{2}$ and killed by cervical dislocation. The trial protocol was approved by the ethical committee of the University of Helsinki, Finland.

\section{Diets}

A low-fibre diet (calculated fibre content $1 \%$,w/w) was prepared for the rats (standard rat chow contains approximately $3.5 \%(\mathrm{w} / \mathrm{w})$ crude fibre and $58 \%(\mathrm{w} / \mathrm{w}) \mathrm{N}$-free extract). The amounts of energy coming from different sources were calculated as 32, 31 and $36 \%$ for carbohydrates, protein and fat, respectively. The control diet contained $(\%, \mathrm{w} / \mathrm{w})$ : peeled potatoes, 38.5 ; minced beef, 23.3; white wheat bread, 8.1; eggs, 20.4; butter, 1.6; sugar, $8 \cdot 1$. The ingredients were homogenised, mixed and baked in a steam oven at $200^{\circ} \mathrm{C}$ for $2-3 \mathrm{~h}$. The mixture was allowed to cool to room temperature and the following ingredients were mixed in $(\%, \mathrm{w} / \mathrm{w})$ : vitamin mixture (1324; Altromin International, Lage, Germany), 0.87; cholesterol (Sigma, St Louis, MO, USA), 0.377; salt $(\mathrm{NaCl}), 2 \cdot 0$. The diets were stored at $-20^{\circ} \mathrm{C}$.

The following feed analyses results were obtained with bomb calorimetry, inductively coupled plasma emission spectrometry and ion chromatography: heat value, $6.49 \mathrm{~kJ} / \mathrm{g}$; DM, 34.2\%; ash, 0.91\%; Na, $0.64 \mathrm{mg} / \mathrm{g}$; Ca, $0.1 \mathrm{mg} / \mathrm{g} ; \mathrm{K}, 3.2 \mathrm{mg} / \mathrm{g} ; \mathrm{Mg}, 0.2 \mathrm{mg} / \mathrm{g} ; \mathrm{Cl}, 1.2 \mathrm{mg} / \mathrm{g}$; phosphate, $2.5 \mathrm{mg} / \mathrm{g}$. The total fat content in the diet was $4.8 \%$. The fatty acid profile was analysed by GC. The basal diet had a total fatty acid content of $3.5 \%$, a saturated fatty acid content of $1.7 \%$ and an unsaturated fatty acid content of $1.8 \%$. The saturated:unsaturated fatty acid ratio was 0.9 .

Polydextrose (Litesse Ultra, lot no. V68011; Danisco Sweeteners Ltd, Redhill, Surrey, UK) and lactitol (Xyrofin N125/22459; Redhill, Surrey, UK) were added in the basal diet at a $2 \%(\mathrm{w} / \mathrm{w})$ concentration, which was calculated on the basis of human fibre intake recommendations $(25-35 \mathrm{~g}$ / d) and the energy requirements of rats. Based on the energy value of the basal diet the feed consumption of a rat was approximated at $40 \mathrm{~g} / \mathrm{d}$. The fibre content of the diet was then designed to be at a moderate $2 \%$ level $(20 \mathrm{~g} / \mathrm{kg}$ diet). This was also the level of fibre that had previously been used in trials studying its degradation in rats (Djouzi et al. 1995). Oku et al. (1991) reported that $3 \%$ PDX did not cause diarrhoea in rats.

\section{Sampling}

DM and $\operatorname{IgA}$ measurements were taken from individual ileal and caecal digesta samples (see later; p. 906). The rest of the caecal digesta was divided into pools (three animals per pool) for the analysis of SCFA, biogenic amines, total microbial counts and $\% \mathrm{G}+\mathrm{C}$ analysis. The samples were stored at $-20^{\circ} \mathrm{C}$ until analysis. $\mathrm{pH}$ was measured from the caecum at sampling with a ROSS combination pH electrode (model 82-63 PerHecT; Woburn, MA, USA). Intestinal tissue samples for histological and immunohistological analysis were obtained from the ileum and distal caecum. The sample was placed in a Tissue-Tek ${ }^{\circledR}$ OCT (Sakura Finetek, Zoeterwoude, The Netherlands), frozen in liquid $\mathrm{N}_{2}$ and stored at $-70^{\circ} \mathrm{C}$. The tissue samples were then cut with a cryostat microtome at $7 \mu \mathrm{m}$, and the slices were placed on SuperFrost ${ }^{\circledR}$ microscope slides (Menzel-Gläser, Braunschweig, Germany), air-dried and stored at $-70^{\circ} \mathrm{C}$ until antibody staining (see later; p. 907).

\section{Chemical analyses from digesta}

The DM content of digesta was determined by weighing before and after drying at $105^{\circ} \mathrm{C}$ for $2 \mathrm{~h}$. The SCFA in digesta were analysed as follows: an internal standard ( $1 \mathrm{ml} ; 20 \mathrm{~mm}$-pivalic acid) and $5 \mathrm{ml}$ water were added to $1 \mathrm{~g}$ of the sample. After thorough mixing, the sample was centrifuged at $5000 \mathrm{~g}$ for $5 \mathrm{~min}$. Following centrifugation, $0.250 \mathrm{ml}$ saturated oxalic acid solution was added to $0.500 \mathrm{ml}$ of the supernatant fraction and the mixture was incubated at $4^{\circ} \mathrm{C}$ for $60 \mathrm{~min}$, then centrifuged at $16000 \mathrm{~g}$ for $5 \mathrm{~min}$. The supernatant fraction was analysed by GC as described previously (Holben et al. 2002). 
The concentrations of acetic acid, propionic acid, butyric acid, isobutyric acid, valeric acid, isovaleric acid, 2methylbutyric acid and lactic acid were determined. Biogenic amines were determined from caecal digesta samples according to Saarinen (2002).

\section{Microbial analyses}

In order to determine the total number of microbes in caecal digesta samples, the cells were separated from the collected digesta by differential centrifugation (Apajalahti et al. 1998). For counting, a sample of separated bacterial cells from each caecum digesta pool (four per treatment, sixteen altogether) was appropriately diluted and the cells were stained with a fluorescent, nucleic acid-binding dye (Syto 24; Molecular Probes Inc, Eugene, USA) (Apajalahti et al. 2002). Microbial numbers were determined by flow cytometry as previously described (Apajalahti et al. 2002). The results were reported as cells/g wet caecal digesta.

The microbial $\% \mathrm{G}+\mathrm{C}$ profiling procedure was followed using the steps described in Apajalahti et al. (1998). In short, bacteria were separated from digesta samples by differential centrifugation. DNA was then recovered from the bacterial cells by a combination of physical, chemical and enzymic lyses. DNA recovered from the total microbial community was then profiled based on the guanine+cytosine content of the chromosomal DNA in the individual bacterial members of the community. Individual chromosomal DNA with different guanine+cytosine contents were separated by $\mathrm{CsCl}$ density gradient centrifugation and the abundance of DNA monitored by pumping the solution through a UV flow cell. The $\% \mathrm{G}+\mathrm{C}$ profiling technique is a culture-independent method capable of depicting the total bacterial community within the gastrointestinal tract in a single analysis. This method is capable of revealing large-scale shifts in the microbial community as a response to dietary changes (Apajalahti et al. 1998, 2002) without the need for conventional plating techniques. This means that changes in the entire microbial community are seen at one glance, even when of unknown identity. More resolution can be achieved when $\% \mathrm{G}+\mathrm{C}$ profiling is combined with, for example, 16S rDNA sequence analysis (Apajalahti et al. 2002).

\section{Immunological analyses}

Individual digesta samples were treated with equal volumes of $1.0 \%(\mathrm{w} / \mathrm{v})$ bovine serum albumin solution in $50 \mathrm{mM}-$ tri(hydroxymethyl)-aminomethane $(\mathrm{pH} 7 \cdot 5)-0 \cdot 15 \mathrm{M}-\mathrm{NaCl}$ for $60 \mathrm{~min}$ at room temperature. The samples were then briefly centrifuged at $50000 \mathrm{~g}$ and the supernatant fractions were used for IgA measurement. Ig A was determined with ELISA utilising specific antibodies and standard samples obtained from Bethyl Laboratories, Inc. (Montgomery, TX, USA) according to the manufacturer's instructions. The results are expressed as $\mu \mathrm{g}$ Ig A/g digesta (wet weight).

Frozen sections of ileum and caecum were stained immunohistochemically to indicate the presence of IL-1(Serotec Ltd, Oxford, UK), TGF- $\beta$ - and TNF- $\alpha$ - (both from R\&D Systems, Minneapolis, MN, USA) positive cells in the mucosa. Antibodies were used at 1:100 dilutions. Goat anti-mouse antibodies (Southern Biotechnology Associates, Birmingham, AL, USA) were used as a secondary antibody (1:400 dilution). The cells were visualised by ABC Vectastain Elite kit PK-6100 system (Vector Laboratories, Inc., Burlingame, CA, USA). The enumeration of positively stained cells was done with image-based analysis (ImagePro 3.0; Media Cybernetics, Silver Spring, MD, USA) from photographed, microscopically randomly chosen sectors of tissue sections. Digesta particles, artefacts and connective tissue were removed with a photo editor before counting. The abundance of positive cells is expressed as a percentage of villus and crypt area of the mucosa.

\section{Histomorphometrical measurements}

The crypt:villus ratio of the ileum was determined from light micrographs by measuring the height of the crypts and villi. Areas where the plane of sections showed the ileal villi in their full length were selected for the measurements.

\section{Statistical analysis}

In order to analyse the effects of treatments on $\% \mathrm{G}+\mathrm{C}$ profiles, the $\% \mathrm{G}+\mathrm{C}$ profile was divided into twelve $\% \mathrm{G}+\mathrm{C}$ increments, each covering $5 \%$. The proportion of microbes with $\% \mathrm{G}+\mathrm{C}$ belonging to a certain range of $\% \mathrm{G}+\mathrm{C}$ was calculated integrating the fractions from the $\% \mathrm{G}+\mathrm{C}$ profile (Apajalahti et al. 2001).

Multiple linear regression. Relationships between a single response ( $y$ variable) and scaled (from 0 to 1) $x$ variables were analysed by multiple linear regression modelling (SYSTAT for Windows, version 5 edition; SPSS Inc., Chicago, IL, USA). The multiple linear regression model used for pooled data was:

$$
y_{\mathrm{i}}=\mathrm{C}_{00}+\mathrm{C}_{01} \times \mathrm{Lac}+\mathrm{C}_{02} \times \mathrm{PDX}+\mathrm{C}_{03} \times \mathrm{Lac}+\mathrm{PDX},
$$

where Lac is $(0,1)$, the variable that gets the value 1 for treatments where lactitol was amended (lactitol and lactitol+PDX); PDX is $(0,1)$, the variable that gets the value 1 for treatments where PDX was amended (PDX and lactitol+PDX); Lac+PDX is $(0,1)$, the variable that gets the value 1 for treatments where both lactitol and PDX were amended (lactitol+PDX); $\mathrm{C}_{00}, \mathrm{C}_{01}, \mathrm{C}_{02}$ and $\mathrm{C}_{03}$ are model parameters.

The multiple linear regression model essentially gives identical results to ANOVA.

The relative increase or decrease of certain treatments compared with the control treatment and the $P$ value associated with that change are reported.

\section{Results}

The growth of rats during the 3-week period did not differ between the dietary groups (Table 1). The addition of PDX, lactitol or their combination significantly decreased the caecal $\mathrm{pH}(P<0 \cdot 0001)$ (Table 1$)$. PDX significantly 
Table 1. Weight gain during 3 weeks, caecal $\mathrm{pH}$, caecal dry matter and ileal dry matter (twelve rats per group) $\dagger$ (Mean values with their standard errors)

\begin{tabular}{|c|c|c|c|c|c|c|c|c|}
\hline \multirow{2}{*}{ Group... } & \multicolumn{2}{|c|}{ Control } & \multicolumn{2}{|c|}{ PDX } & \multicolumn{2}{|c|}{ Lactitol } & \multicolumn{2}{|c|}{ PDX+lactitol } \\
\hline & Mean & SE & Mean & SE & Mean & SE & Mean & SE \\
\hline Growth (g) & $134 \cdot 2$ & $3 \cdot 1$ & $129 \cdot 2$ & 3.6 & $131 \cdot 9$ & $3 \cdot 3$ & $124 \cdot 7$ & 3.2 \\
\hline Caecum pH & $6 \cdot 39$ & 0.05 & $5 \cdot 70^{*}$ & 0.09 & $5 \cdot 85^{\star}$ & 0.06 & $5 \cdot 81^{*}$ & 0.11 \\
\hline Caecum DM $(\%)$ & $19 \cdot 41$ & 0.25 & $22 \cdot 14^{\star}$ & 0.37 & $20 \cdot 21$ & 0.39 & $20 \cdot 23$ & 0.26 \\
\hline Ileum DM¥ (\%) & 19.93 & 0.21 & $21.52^{*}$ & 0.27 & $20 \cdot 43$ & $0 \cdot 16$ & $20 \cdot 43$ & 0.51 \\
\hline
\end{tabular}

PDX, polydextrose

* Mean value was statistically significantly different from that for the control $(P<0.01)$

†For details of diets and procedures, see p. 906

fDM content calculated from four pools.

increased the DM content of ileal $(P=0.002)$ and caecal $(P=0.0001)$ digesta (Table 1$)$.

PDX alone and in combination with lactitol reduced the concentrations of total SCFA in the caecum. However, the effect was statistically significant only in the combination $(P<0.0001$; Table 2). The concentration of acetic acid was significantly reduced by PDX $(23 \% ; P<0 \cdot 0001)$, lactitol $(15 \%, P=0.0005)$, and their combination $(38 \%$, $P=0.0005$; Table 2). Lactitol increased the concentration of butyric acid by $187 \%(P<0.0001)$, while together with PDX the increase from control was $70 \%$ $(P<0 \cdot 0001)$. PDX $(P<0.0001)$, lactitol $(P<0.0001)$ and their combination $(P=0.0002$ to $P=0.002)$ significantly reduced the concentrations of branched SCFA isobutyric acid, 2-methylbutyric acid and isovaleric acid (Table 2). Lactic acid concentration was significantly increased by the addition of lactitol $(46 \%, P=0.02)$, whereas the addition of PDX in combination with lactitol significantly reduced it $(39 \%, P=0.0003)$. The relative amount of acetic acid was significantly reduced by the addition of PDX, lactitol or their combination $(P<0.001)$, while that of propionic acid increased significantly (Table 2$)$. Lactitol alone or in combination with PDX significantly increased the relative amount of butyric acid $(P<0.001)$. For lactic acid, the relative changes were small, yet significant by the addition of lactitol (increase; $P<0.05$ ) and combination of PDX and lactitol (decrease; $P<0.05$ ). The relative amount of branched SCFA was reduced by the addition of lactitol, PDX or their combination $(P<0 \cdot 01)$.

The total number of microbes in the caecum decreased significantly when PDX, lactitol or their combination were added in the diet; the reduction was $22 \%$ $(P=0.009), \quad 24 \% \quad(P=0.004)$, and $13 \% \quad(P=0.006)$, respectively (Table 3 ). All dietary treatments changed the structure of the caecal microbial community, but the combination of PDX and lactitol had a stronger effect on the microbial community than either of them alone. Both PDX and lactitol increased the abundance of bacteria within $\% \mathrm{G}+\mathrm{C} \quad 40-44$ by $27 \% \quad(P=0.01)$ and $24 \%$ $(P=0.02)$, respectively (Figs. 1 (a) and (b)). The PDX+ lactitol diet resulted in a $32 \%$ increase in the $\% \mathrm{G}+\mathrm{C}$ 35-39 area $(P<0.0001)$, and a $15 \%$ increase in the $\% \mathrm{G}+\mathrm{C} 45-49$ area $(P=0 \cdot 0002)$. Also, the PDX+lactitol diet resulted in a 35-49\% reduction in a wide area of $\% \mathrm{G}+\mathrm{C} 50-74(P=0.0003$ between area $\% \mathrm{G}+\mathrm{C} 65-74)$ in comparison with the control (Fig. 1 (c)). The PDX diet resulted in a maximum of $22 \%$ reduction in the area between $\% \mathrm{G}+\mathrm{C} 50-69(P=0.0001$ at $\% \mathrm{G}+\mathrm{C} 55-59)$. The lactitol diet also gave a significant reduction in the area between $\% \mathrm{G}+\mathrm{C} 50-59(P=0.001)$ (Figs. 1 (a) and (b)).

The concentrations of biogenic amines and their relative changes with different diets in the caecum are given in Table 4. The sum of biogenic amines reduced by $12 \%$ with the combination of PDX and lactitol $(P=0.03$; Table 4). The highest residual concentrations of individual biogenic amines were measured for spermidine and methylamine. Methylamine concentrations were decreased significantly by the addition of PDX, lactitol and their combination (Table 4). Lactitol alone significantly increased the concentration of spermidine but in combination with PDX it was significantly reduced. The concentration of putrescine was increased significantly by PDX, lactitol and their combination. Tyramine concentration was increased by PDX and by the PDX+lactitol combination but was reduced by lactitol (Table 4). Lactitol, PDX and their combination significantly increased the concentration of histamine in the caecal digesta (Table 4).

There were no significant differences in the crypt:villus ratio of rat small intestine with the different diets indicating a lack of irritating stimulus on the epithelium. The crypt:villus ratios were: control, 0.53 (SE 0.04); PDX group, 0.53 (SE 0.05); lactitol group, 0.50 (SE 0.06); PDX+lactitol group, 0.55 (SE 0.04). However, PDX, lactitol and their combination significantly $(P<0.01)$ reduced the villus height $(\mu \mathrm{m})$ : control, 135.83 (SE 10.61); PDX group, 98.15 (SE 5.19); lactitol group, 105.00 (SE 7.62); PDX+lactitol group, 96.48 (SE 8.83). Similarly, the crypt depth reduced significantly $(P<0.05)$ in these groups $(\mu \mathrm{m})$ : control, 70.63 (SE 7.24); PDX group, 52.41 (SE 4.86); lactitol group, 50.19 (SE 4.15); PDX+lactitol group, 52.59 (SE 4.98).

Diet had no effect on the $\operatorname{Ig}$ A concentrations in the rat ileum. However, the concentration of $\mathrm{Ig} \mathrm{A}$ in the caecum increased several-fold $(345 \%)$ by PDX $(P=0.007)$, and by the combination PDX+lactitol $(996 \%, P<0.0001$; Fig. 2). PDX alone increased the ileal IL-1-positive cells significantly $(P=0.007)$ but, when combined with lactitol, no effects were seen (Table 5). The test diets had no effect on the IL-1-positive or TNF- $\alpha$-positive cells in the caecum when compared with the control diet. Lactitol increased the area of TGF- $\beta$-positive cells in the caecum 


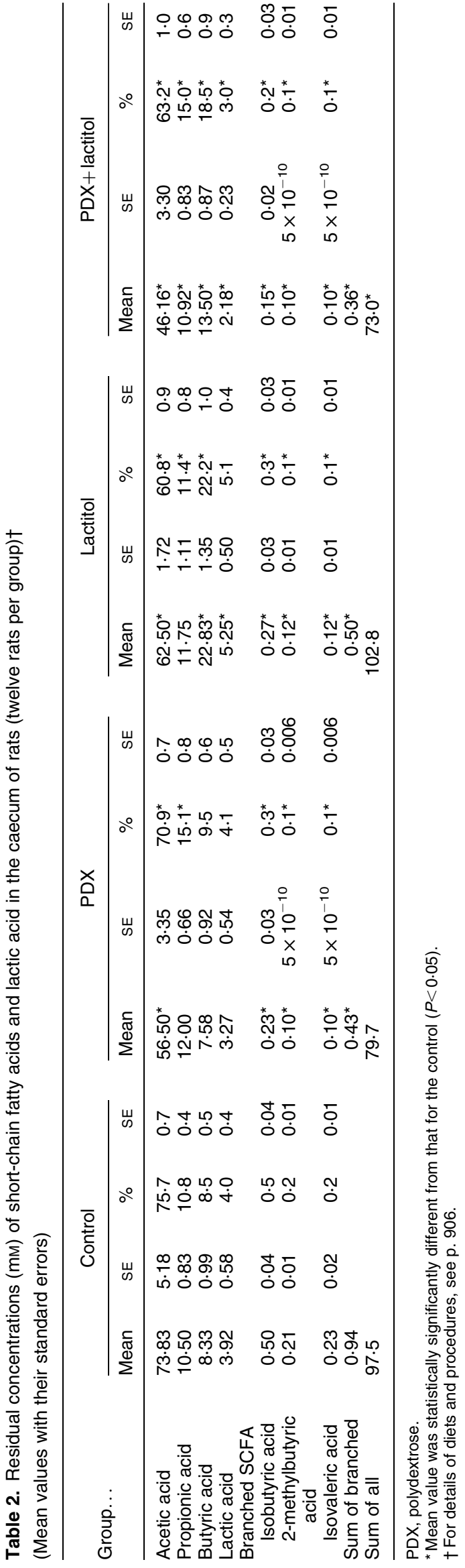

Table 3. Bacterial density in the caecum of rats fed on different diets (four samples per group) $\dagger$ (Mean values with their standards errors)

\begin{tabular}{llc}
\hline \multirow{2}{*}{ Group } & \multicolumn{2}{l}{ Cell no. (per g digesta) } \\
\cline { 2 - 3 } & Mean & SE \\
\hline Control & $1 \cdot 02^{11}$ & $5 \cdot 37^{9}$ \\
PDX & $8.06^{10^{\star}}$ & $2 \cdot 67^{9}$ \\
Lactitol & $7 \cdot 70^{10^{\star}}$ & $7.09^{9}$ \\
PDX+lactitol & $8 \cdot 68^{10^{*}}$ & $4.34^{9}$
\end{tabular}

PDX, polydextrose.

* Mean value was statistically significantly different from

that for the control $(P<0.001)$.

†For details of diets and procedures, see p. 906.
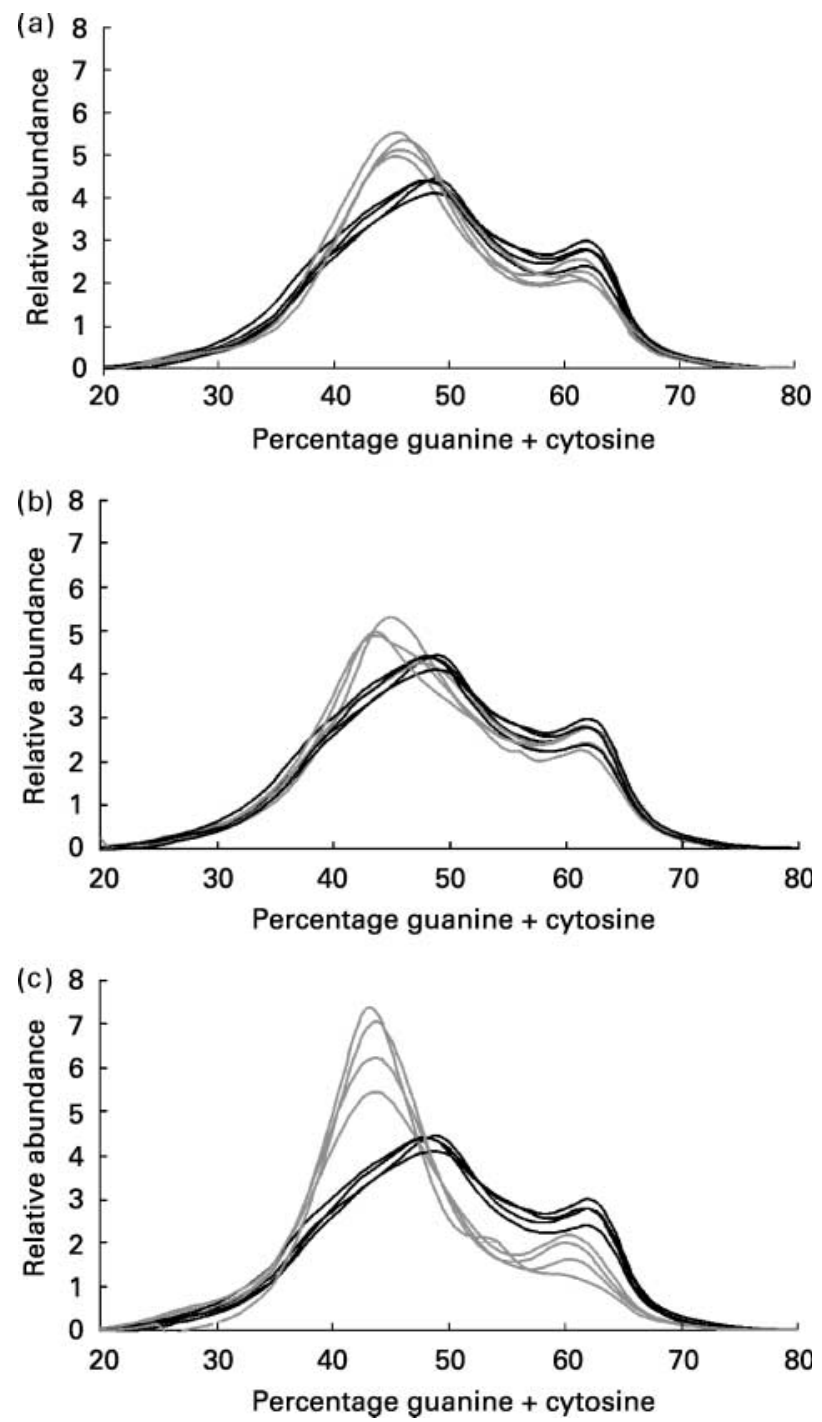

Fig. 1. Effect of polydextrose (PDX), lactitol and their combination on the structure of the total microbial community in rat caecum. Chromosomal DNA of caecal bacteria was purified from individual rats and analysed by percentage guanine + cytosine profiling. (a), PDX diet; (b), lactitol diet; (c), PDX + lactitol diet; (-), rats fed on control diet; $(--)$ rats fed on test diets. 
Table 4. Concentrations of biogenic amines in the caecum ( $\mu \mathrm{M})$ of rats fed on different diets (twelve rats per group) ${ }^{\star}$ (Mean values with their standard errors)

\begin{tabular}{|c|c|c|c|c|c|c|c|c|c|c|c|}
\hline \multirow{2}{*}{ Group... } & \multicolumn{2}{|c|}{ Control } & \multicolumn{3}{|c|}{ PDX } & \multicolumn{3}{|c|}{ Lactitol } & \multicolumn{3}{|c|}{ PDX+ lactitol } \\
\hline & Mean & SE & Mean & SE & $P<\dagger$ & Mean & SE & $P<\dagger$ & Mean & SE & $P<\dagger$ \\
\hline Methylamine & 173.5 & $14 \cdot 3$ & $118 \cdot 5$ & $6 \cdot 7$ & 0.0001 & $139 \cdot 4$ & $12 \cdot 0$ & 0.01 & $97 \cdot 4$ & $4 \cdot 8$ & 0.01 \\
\hline Agmatine & $51 \cdot 2$ & 3.9 & 34.8 & 6.4 & 0.0001 & $61 \cdot 1$ & $4 \cdot 2$ & & $32 \cdot 1$ & $2 \cdot 0$ & 0.0001 \\
\hline Ethylamine & $2 \cdot 1$ & 0.2 & 2.5 & 0.2 & & 1.6 & 0.6 & & 1.9 & $0 \cdot 0$ & \\
\hline Tryptamine & $8 \cdot 4$ & 0.4 & 8.5 & 0.7 & & $11 \cdot 6$ & 0.9 & 0.01 & $9 \cdot 3$ & $1 \cdot 3$ & \\
\hline Buthylamine & 1.9 & $0 \cdot 2$ & $2 \cdot 1$ & 0.2 & & $2 \cdot 4$ & 0.1 & & $3 \cdot 0$ & $0 \cdot 2$ & 0.001 \\
\hline Putrescine & 29.9 & $5 \cdot 4$ & 71.6 & $12 \cdot 6$ & 0.01 & $60 \cdot 7$ & $13 \cdot 8$ & 0.05 & $52 \cdot 4$ & $5 \cdot 1$ & 0.05 \\
\hline Cadaverine & $1 \cdot 7$ & 0.2 & $4 \cdot 1$ & 0.2 & 0.001 & 2.7 & 0.4 & & 3.4 & 0.4 & 0.0001 \\
\hline Histamine & $19 \cdot 9$ & 1.6 & $33 \cdot 8$ & $5 \cdot 7$ & 0.001 & $33 \cdot 3$ & $4 \cdot 1$ & 0.001 & $59 \cdot 1$ & $8 \cdot 6$ & 0.001 \\
\hline Tyramine & $12 \cdot 4$ & $2 \cdot 6$ & $38 \cdot 8$ & 0.7 & 0.0001 & $4 \cdot 8$ & 3.5 & 0.01 & $27 \cdot 9$ & 3.5 & 0.01 \\
\hline Spermidine & 211.8 & 6.5 & $200 \cdot 6$ & $5 \cdot 0$ & & $232 \cdot 1$ & $9 \cdot 0$ & 0.01 & $172 \cdot 9$ & $9 \cdot 6$ & 0.001 \\
\hline Spermine & $19 \cdot 5$ & $1 \cdot 0$ & 20.9 & 3.0 & & $33 \cdot 8$ & $2 \cdot 0$ & 0.0001 & $30 \cdot 8$ & $3 \cdot 1$ & \\
\hline Total & 1058 & 37 & 1025 & 46 & & 1103 & 40 & & 934 & 30 & 0.03 \\
\hline
\end{tabular}

PDX, polydextrose

${ }^{*}$ For details of diets and procedures, see p. 906.

† Level of significance of difference from that for the control.

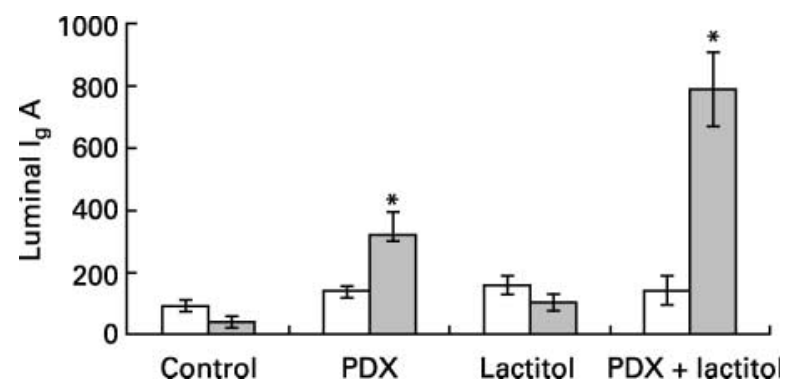

Fig. 2. Concentrations of luminal Ig $A$ in the ileum ( $\square$ ) and caecum $(\square)$ of rats fed on different diets (twelve rats per group). Values are means, with their standard errors represented by vertical bars. * Mean value was significantly different to that for the control group: $P=0.007$ for polydextrose (PDX); $P<0.0001$ for PDX+lactulose.

by $40 \%(P=0 \cdot 02)$. A similar increase was also seen in caecal TGF- $\beta$-positive cells in combination with PDX $(P=0.02)$.

\section{Discussion}

As a general rule carbohydrates are a preferred $\mathrm{C}$ source for bacteria. Therefore, simple carbohydrates may become depleted before reaching the transverse colon. When this happens the main energy source in the distal (descending) colon is protein or complex carbohydrates (Cummings et al. 1987). Saccharolytic reactions can be characterised by the high production of acidic endproducts, resulting in the acidification of the colonic contents. In putrefactive reactions, basic endproducts are formed and therefore the $\mathrm{pH}$ of the lumen of the distal colon is closer to neutral. Putrefactive metabolic pathways produce branched SCFA, $\mathrm{NH}_{3}$, biogenic amines and indoles (Macfarlane et al. 1986; Cummings \& Macfarlane, 1991; Smith \& Macfarlane, 1997). In the present study the tested compounds, i.e. PDX, lactitol and their combination, reduced the caecal $\mathrm{pH}$ of rats indicating caecal fermentation. Previous studies also show $\mathrm{pH}$ reduction by $\mathrm{PDX}$ and lactitol alone (Yoshioka et al. 1994; Piva et al. 1996; Hara et al. 2000). The most probable explanation for the observed $\mathrm{pH}$ reduction is bacterial fermentation of the carbohydrates.

PDX and lactitol reduced $\mathrm{pH}$ but had no significant effect on the residual SCFA concentrations in the present study. PDX at the concentration of $5 \%$ had a similar $\mathrm{pH}$-lowering effect without a concomitant increase in SCFA concentrations in the study of Hara et al. (2000). They also observed that the volume of the caecum increased significantly with a

Table 5. Relative (\%) area of cells producing cytokines interleukin-1, tumour necrosis factor- $\alpha$ and transforming growth factor (TGF)- $\beta$ in the ileal and caecal mucosa of rats fed on different diets (eight to nine rats per group) $\dagger$ (Mean values with their standard errors)

\begin{tabular}{|c|c|c|c|c|c|c|c|c|c|}
\hline \multirow{2}{*}{ Group. . } & & \multicolumn{2}{|c|}{ Control } & \multicolumn{2}{|c|}{ PDX } & \multicolumn{2}{|c|}{ Lactitol } & \multicolumn{2}{|c|}{ PDX+lactitol } \\
\hline & & Mean & SE & Mean & SE & Mean & $\mathrm{SE}$ & Mean & SE \\
\hline \multirow[t]{2}{*}{ IL-1 } & Ileum & 0.38 & 0.08 & $0.79^{*}$ & 0.07 & 0.50 & 0.08 & 0.47 & 0.08 \\
\hline & Caecum & 1.13 & 0.26 & 1.18 & 0.25 & 1.03 & 0.14 & 1.23 & 0.18 \\
\hline \multirow[t]{2}{*}{ TNF- $\alpha$} & Ileum & 0.65 & 0.09 & 0.75 & 0.13 & 0.79 & 0.13 & 0.76 & 0.17 \\
\hline & Caecum & 0.99 & 0.09 & 1.08 & 0.13 & 1.27 & 0.17 & 1.05 & 0.22 \\
\hline \multirow{2}{*}{ TGF- $\beta$} & Ileum & 0.63 & 0.13 & 0.51 & 0.11 & 0.64 & 0.13 & 0.44 & 0.13 \\
\hline & Caecum & 0.91 & 0.05 & 0.89 & 0.07 & $1.33^{*}$ & 0.13 & $1 \cdot 18^{*}$ & 0.26 \\
\hline
\end{tabular}

PDX, polydextrose.

* Mean value was statistically significantly different from that for the control $(P<0.05)$.

†For details of diets and procedures, see p. 906. 
PDX diet. One possible explanation for the $\mathrm{pH}$ reduction in the present experiment with PDX and lactitol is that the products of putrefaction in the digesta reduced even more. Indeed, the combination of PDX and lactitol significantly reduced the production of biogenic amines. Endo et al. (1991) observed that PDX supplementation in a Western diet reduced faecal $\mathrm{pH}$ and also decreased putrefactive biomarkers in human subjects. Mitsuoka (1996) saw a decrease in faecal putrefactive metabolites ( $\mathrm{p}$-cresol, indole, isobutyric and isovaleric acids), together with lower faecal $\mathrm{pH}$. This can be considered beneficial since amines have been associated with a number of intestinal and systemic diseases (see Smith \& Macfarlane, 1997).

In our control ('human') diet, the molar ratio of butyrate was approximately $10 \%$, which is somewhat lower than that of $17 \%$ in the studies of Cheng et al. (1987) and Remesy \& Demigne (1976). In the study of Goodlad \& Mathers (1990) the molar concentration of butyrate was $14 \%$. Lactitol alone significantly increased the residual butyrate molar ratio to $22 \%$ from $8 \%$ with the control diet. In the PDX+lactitol group the molar increase was also significant. Apajalahti et al. (2002) observed that soluble fibre, $10 \%$ inulin, did not increase butyrate production in mice with a semi-synthetic casein diet (molar ratio $3 \%$ ), while in the starter diet (commercial rodent pellets) the butyrate molar ratio was $20 \%$.

Butyrate is the preferred source of energy for colonocytes, which also improves the integrity of the mucosa, and appears to protect against colorectal cancer (Gamet et al. 1992; Smith et al. 1998; Abrahamse et al. 1999). A butyric acid analogue, tributyrin, is capable of inducing differentiation and enhancing apoptosis in malignant cells (Schroeder \& Maurer, 2002). Piva et al. (2002) observed that tributyrin and lactitol had synergistic effects in the intestine of piglets. One notable observation was that these two compounds together decreased histamine levels in the jejunum and caecum, indicating a change in the putrefactive metabolism of pigs. Since PDX has been shown to increase butyric acid production in human subjects (Jie et al. 2000), combining it with lactitol could potentially enhance the integrity of the intestinal epithelium.

Based on the reduction of spermidine by lactitol and the PDX+lactitol combination, one could anticipate a reduction in the number of bacterial groups that produce biogenic amines, namely anaerobic cocci, fusobacteria and bacteroides (Noack et al. 1998). However, since no specific microbial groups were identified in the present study, the source of biogenic amines, whether originating from microbes or the animal itself (Seiler et al. 1998; Delzenne et al. 2000), remains speculative.

In the present study the total bacterial density in the caecum was reduced by all dietary treatments but PDX or lactitol should not directly inhibit colonic microflora. A lower bacterial density then hints towards the dilution of digesta and/or its faster transit in the gastrointestinal tract (see Govers et al. 1999). An enlargement of the caecal volume is one explanation for the reduced SCFA concentrations (for example, see Cheng et al. 1987). Caecal weight was not measured in the present study; an increase in weight would imply a larger volume and possibly dilution of some of the measured compounds. The change in the caecal DM content in the present study was so small that it hardly explains the observed change. Digesta flow was not measured in the present study.

The studied compounds also had significant effects on the structure of the caecal microbial community as indicated by changes in the $\% \mathrm{G}+\mathrm{C}$ profiles. This method is useful since it provides a picture of the total microbial community and changes in response to diet and the environment (Apajalahti et al. 2001). The combination of PDX and lactitol had the strongest effect on the bacterial community composition. The major shift was seen in the bacteria that have $40-50 \%$ guanine and cytosine in their chromosomal DNA. Since several bacterial groups fit this description we cannot use this analysis for the identification of bacterial species. The study by Apajalahti et al. (2002) indicated that large shifts in the $\% \mathrm{G}+\mathrm{C}$ profiles occurred in the caeca of mice fed inulin compared with those fed a control diet. These changes were characterised by $16 \mathrm{~S}$ rRNA sequencing and were found to be caused mainly by previously unknown bacterial species and also completely unknown bacterial genera. Therefore, without further analysis, speculation on the exact identity of microbes behind the changes in $\% \mathrm{G}+\mathrm{C}$ profiles in the present study is not warranted.

Even if the identity remains unknown, the changes in the microflora may have been related to immune stimulation observed in the present study. The increase in the $\% \mathrm{G}+\mathrm{C}$ area of $40-44$ had a positive correlation with the increase in secretory $\operatorname{Ig}$ A $(P<0 \cdot 01)$. The presently observed connection between intestinal microbes and local immune responses is strengthened by the previous finding in which some species of Lactobacillus, also residing in the $\% \mathrm{G}+\mathrm{C}$ area of $40-44$, stimulated Ig A production when added to the diet (Kaila et al. 1992). Secretion of Ig A can be induced also by supplementing the diet with fibre since PDX alone significantly increased Ig A production in the lower intestine while the combination of PDX+lactitol further increased this response almost ten-fold compared with the control. The mechanism behind this synergistic effect is unknown. The additional stimulation of Ig A secretion of the PDX and lactitol combination, in comparison with PDX alone, may be explained by the boost of energy (butyrate) for immune and epithelial cells provided by lactitol (see also Schely \& Field, 2002) and/or by the ability of lactitol to induce TGF- $\beta$ production in mucosal cells. TGF- $\beta$, among many other effects, promotes the switching of B cells to producing Ig A (Coffman et al. 1989).

In the present study there were no changes in the crypt:villus ratio of the rats fed on the different dietary treatments. The villus length:crypt depth ratio can be used as a sensitive indicator of product safety and it has been shown to be very sensitive to gastrointestinal pathogens (Larkin \& Hannan, 1984; Keenan et al. 1986) and dietary changes (Southon et al. 1985; Sagher et al. 1991; Galluser et al. 1993). Interestingly, both the villus height and crypt depth reduced significantly when PDX, lactitol or their combination was added to the diet. High-viscosity carboxymethylcellulose reduced villus height in pigs while the low-viscosity counterpart increased 
it (McDonald et al. 2001). Dirks \& Freeman (1987) observed that $4.5 \%$ and $9.0 \%$ cellulose, pectin or hemicellulose increased villus height in rat jejunum or ileum. The significance of these differences is unclear at present. Yet, in the present study, no signs of inflammation were seen in the histomorphometric parameters.

Chronic intestinal inflammations are increasingly common, such as, for example, some food allergies or irritable bowel disease. Furthermore, a continuous inflammation in the colon is associated with an increased risk for colon cancer (Levin, 1992).

The T-lymphocytes secreting TGF- $\beta$ in the lower gastrointestinal tract are thought to be associated with the enhanced function of the epithelial barrier (Roche et al. 2000). Lactitol alone and in combination with PDX significantly increased the presence of these cells in the caecum. Since lactitol also appeared to stimulate butyric acid in the caecum, it seems justified to say that lactitol promoted the integrity of the epithelial barrier in the present study. The relative area of cells producing IL-1 was increased by the addition of PDX. IL-1 is generally considered as a pro-inflammatory cytokine; it can be detected in the intestinal mononuclear cells of patients with chronic intestinal inflammation (Olson et al. 1993). However, the role of IL-1 in the intestine is not clearly understood. IL-1 is secreted by normal intestinal tissue (Gionchetti et al. 1992). Furthermore, intestinal epithelial cells express IL-1 receptors (McGee et al. 1996) and IL-1 has been suggested to counteract non-steroid anti-inflammatory drug-induced mucosal damage in the gut (Gyires, 1994). We believe that the increase in IL-1-producing cells in the present study was not associated with inflammatory processes since the number of TNF- $\alpha$-producing cells did not increase concomitantly and no indications of inflammation were seen in the tissue slices. Finally, non-inflammatory responses such as Ig A secretion were clearly induced. When assessing the role of dietary fibre on intestinal mucosa, it is clearly important to realise the presence of various types of immune responses and measure them accordingly.

In conclusion, PDX showed effects in rats that are associated with dietary fibre. The combination of PDX + lactitol caused changes in the rat gastrointestinal tract that were distinct from those caused by these molecules alone. Shifts in the microflora with an associated change in the microbial metabolism, including butyrate production and reduction in putrefaction, could possibly reduce the risk of colon carcinogenesis. Also, a very significant increase in the luminal Ig A concentration is an important indication of a potentially improved immune defence.

\section{References}

Abrahamse SL, Pool-Zobel BL \& Rechkemmer G (1999) Potential of short chain fatty acids to modulate the induction of DNA damage and changes in the intracellular calcium concentration by oxidative stress in isolated rat distal colon cells. Carcinogenesis 20, 629-634.

Apajalahti JHA, Sarkilahti LK, Maki BR, Heikkinen JP, Nurminen PH \& Holben WE (1998) Effective recovery of bacterial
DNA and percent-guanine-plus-cytosine-based analysis of community structure in the gastrointestinal tract of broiler chickens. Appl Environ Microbiol 64, 4084-4088.

Apajalahti JHA, Kettunen A, Bedford MR \& Holben WE (2001) Percent $\mathrm{G}+\mathrm{C}$ profiling accurately reveals diet-related differences in the gastrointestinal microbial community of broiler chickens. Appl Environ Microbiol 67, 5656-5667.

Apajalahti JHA, Kettunen H, Kettunen A, Holben WE, Nurminen PH, Rautonen N \& Mutanen M (2002) Culture-independent microbial community analysis reveals that inulin in the diet primarily affects previously unknown bacteria in the mouse caecum. Appl Environ Microbiol 68, 4986-4995.

Cheng BO, Trimble RP, Illman RJ, Stone BA \& Topping DL (1987) Comparative effects of dietary wheat bran and its morphological components (aleurone and pericarp-seed coat) on volatile fatty acid concentrations in the rat. Br J Nutr 57, 69-76.

Coffman RL, Lebman DA \& Schrader B (1989) Transforming growth factor $\beta$ specifically enhances IgA production by lipopolysaccharide-stimulated murine B lymphocytes. J Exp Med 170, 1039-1044.

Craig SA, Holden JF \& Khaled MY (2001) Determination of polydextrose in foods by ion chromatography: collaborative study. J AOAC Int 84, 472-478.

Cummings JH \& Macfarlane GT (1991) The control and consequences of bacterial fermentation in the human colon. $J$ Appl Bacteriol 70, 443-459.

Cummings JH, Pomare EW, Branch WJ, Naylor CP \& Macfarlane GT (1987) Short chain fatty acids in human large intestine, portal, hepatic and venous blood. Gut 28, 1221-1227.

Delzenne NM, Kok N, Deloyer P \& Dandrifosse G (2000) Dietary fructans modulate polyamine concentrations in the cecum of rats. J Nutr 130, 2456-2460.

Dirks P \& Freeman HJ (1987) Effects of differing purified cellulose, pectin and hemicellulose fiber diets on mucosal morphology in the rat small and large intestine. Clin Invest Med 10, 32-38.

Djouzi Z, Andrieux C, Pelenc V, Somarriba S, Popot F, Paul F, Monsan P \& Szylit O (1995) Degradation and fermentation of alpha-gluco-oligosaccharides by bacterial strains from human colon: in vitro and in vivo studies in gnotobiotic rats. J Appl Bacteriol 79, 117-127.

Endo K, Kumemura M, Nakamura K, Fujisawa T, Suzuki K, Benno Y \& Mitsuoka T (1991) Effect of high cholesterol diet and polydextrose supplementation on the microflora, bacterial enzyme activity, putrefactive products, volatile fatty acid (VFA) profile, weight, and $\mathrm{pH}$ of the feces in healthy volunteers. Bifidobact Microflora 10, 53-64.

Galluser M, Czernichow B, Dreyfus H, Gosse F, Guerold B, Kachelhoffer J, Doffoel M \& Raul F (1993) Comparison of different lipid substrates on intestinal adaptation in the rat. Gut 34, 1069-1074.

Gamet L, Daviaud D, Denis-Pouxviel C, Remesy C \& Murat JC (1992) Effects of short-chain fatty acids on growth and differentiation of the human colon-cancer cell line HT29. Int $J$ Cancer 52, 286-289.

Gionchetti P, Campieri M, Belluzzi A, et al. (1992) Interleukin 1 beta (IL-1 beta) release from fresh and cultured colonic mucosa in patients with ulcerative colitis (UC). Agents Actions (Special Conference Issue) 35, C50-C52.

Goodlad JS \& Mathers JC (1990) Large bowel fermentation in rats given diets containing raw peas (Pisum sativum). $\mathrm{Br} \mathrm{J}$ Nutr 64, 569-587.

Govers MJAP, Gannon NJ, Dunshea FR, Gibson PR \& Muir JG (1999) Wheat bran affects the site of fermentation of resistant starch and luminal indexes related to colon cancer risk: a study in pigs. Gut $\mathbf{4 5}, 840-847$. 
Gyires K (1994) Some of the factors that may mediate or modify the gastrointestinal mucosal damage induced by non-steroidal anti-inflammatory drugs. Agents Actions 41, $73-79$.

Hara H, Suzuki T \& Aoyama Y (2000) Ingestion of the soluble dietary fibre, polydextrose, increases calcium absorption and bone mineralization in normal and total-gastrectomized rats. Br J Nutr 84, 655-661.

Holben WE, Sarkilahti LK, Williams P, Saarinen M \& Apajalahti JHA (2002) Phylogenetic analysis of intestinal microflora indicates a novel Mycoplasma phylotype in farmed and wild salmon. Microb Ecol 44, 175-185.

Jie Z, Bang-Yao L, Ming-Jie X, Hai-Wei L, Zu-Kang Z, TingSong W \& Craig SA (2000) Studies on the effects of polydextrose intake on physiologic functions in Chinese people. Am J Clin Nutr 72, 1503-1509.

Kaila M, Isolauri E, Soppi E, Virtanen E, Laine S \& Arvilommi H (1992) Enhancement of the circulating antibody secreting cell response in human diarrhea by a human Lactobacillus strain. Pediatr Res 32, 141-144.

Keenan KP, Sharpnack DD, Collins H, Formal SB \& O'Brien AD (1986) Morphologic evaluation of the effects of Shiga toxin and E coli Shiga-like toxin on the rabbit intestine. Am $J$ Pathol 125, 69-80.

Kelsall B \& Strober W (1999) Gut-associated lymphoid tissue. Antigen handling and T-lymphocyte responses. In Mucosal Immunology, pp. 293-313 [L Pearay, J Mestecky, ME Lamm, W Strober, J Bienenstock and JR McGhee, editors]. New York: Academic Press.

Larkin HA \& Hannan J (1984) Intestinal absorption and structure in iron deficient piglets. Res Vet Sci 36, 199-204.

Lee A \& Storey DM (1999) Comparative gastrointestinal tolerance of sucrose, lactitol, or D-tagatose in chocolate. Regul Toxicol Pharmacol 29, S78-S82.

Letterio JJ \& Roberts AB (1998) Regulation of immune responses by TGF-beta. Annu Rev Immunol 16, 137-161.

Levin B (1992) Ulcerative colitis and colon cancer: biology and surveillance. J Cell Biochem 16, Suppl., 47-50.

Livesey G, Johnson IT, Gee JM, Smith T, Lee WE, Hillan KA, Meyer J \& Turner SC (1993) 'Determination' of sugar alcohol and polydextrose absorption in humans by the breath hydrogen $\left(\mathrm{H}_{2}\right)$ technique: the stoichiometry of hydrogen production and the interaction between carbohydrates assessed in vivo and in vitro. Eur J Clin Nutr 47, 419-430.

McDonald DE, Pethick DW, Mullan DP \& Hampson DJ (2001) Increasing viscosity of the intestinal contents alters small intestinal structure and intestinal growth, and stimulates proliferation of enterotoxigenic Escherichia coli in newly-weaned pigs. Br J Nutr 86, 487-498.

Macfarlane GT, Cummings JH \& Allison C (1986) Protein degradation by human intestinal bacteria. J Gen Microbiol 132, $1647-1656$.

McGee DW, Vitkus SJ \& Lee P (1996) The effect of cytokine stimulation on IL-1 receptor mRNA expression by intestinal epithelial cells. Cell Immunol 168, 276-280.

Masini A, Efrati C, Merli M, Attili AF, Amodio P, Ceccanti M \& Riggio O (1999) Effect of lactitol on blood ammonia response to oral glutamine challenge in cirrhotic patients: evidence for an effect of nonabsorbable disaccharides on small intestine ammonia generation. Am $J$ Gastroenterol 94, $3323-3327$.

Mitsuoka T (1996) Intestinal flora and human health. Asia Pacific $J$ Clin Nutr 1, 2-9.

Natah SS, Hussien KR, Tuominen JA \& Koivisto VA (1997) Metabolic response to lactitol and xylitol in healthy men. $A m$ J Clin Nutr 65, 947-950.

Noack J, Kleessen B, Proll J, Dongowski G \& Blaut M (1998)
Dietary guar gum and pectin stimulate intestinal microbial polyamine synthesis in rats. J Nutr 128, 1385-1391.

Oku T, Fujii Y \& Okamatsu H (1991) Polydextrose as dietary fiber: hydrolysis by digestive enzymes and its effects on gastrointestinal transit time in rats. J Clin Biochem Nutr 11, $31-40$.

Olson AD, Ayass M \& Chensue S (1993) Tumor necrosis factor and IL-1 beta expression in pediatric patients with inflammatory bowel disease. J Pediatr Gastroenterol Nutr 16, 241-246.

Patil DH, Grimble GK \& Silk DBA (1987) Lactitol, a new hydrogenated lactose derivative: intestinal absorption and laxative threshold in normal human subjects. Br J Nutr 57, 195-199.

Pfizer (1978) Pfizer Inc. Polydextrose Food Additive Petition, FDA petition 9A3441. New York: Pfizer Inc.

Piva A, Panciroli A, Meola E \& Formigoni A (1996) Lactitol enhances short-chain fatty acid and gas production by swine cecal microflora to a greater extent when fermenting low rather than high fiber diets. J Nutr 126, 280-289.

Piva A, Prandini A, Fiorentini L, Morlacchini M, Galvano F \& Luchansky JB (2002) Tributyrin and lactitol synergistically enhanced the trophic status of the intestinal mucosa and reduced histamine levels in the gut of nursery pigs. J Anim Sci 80, 670-680.

Prosky L (2000) When is dietary fiber considered a functional food? Biofactors 12, 289-297.

Remesy C \& Demigne C (1976) Partition and absorption of volatile fatty acids in the alimentary canal of the rat. Ann Vet Res 3, 39-55.

Roche JK, Martins CA, Cosme R, Fayer R \& Guerrant RL (2000) Transforming growth factor beta1 ameliorates intestinal epithelial barrier disruption by Cryptosporidium parvum in vitro in the absence of mucosal T lymphocytes. Infect Immun $\mathbf{6 8}$, $5635-5644$.

Saarinen MT (2002) Determination of biogenic amines as dansyl derivatives in intestinal digesta and feces by reversed phase HPLC. Chromatographia 55, 297-300.

Sagher FA, Dodge JA, Johnston CF, Shaw C, Buchanan KD \& Carr KE (1991) Rat small-intestinal morphology and tissue regulatory peptides: effects of high dietary fat. $\mathrm{Br} J$ Nutr $\mathbf{6 5}$, $21-28$.

Schley PD \& Field CJ (2002) The immune-enhancing effects of dietary fibres and prebiotics. Br J Nutr 87, Suppl. 2, S221-S230.

Schroeder CP \& Maurer HR (2002) Tributyrin-induced differentiation promotes apoptosis of LS 174T colon cancer cells in vitro. Int J Oncol 20, 195-200.

Seiler N, Atanassov CL \& Raul F (1998) Polyamine metabolism as target for cancer chemoprevention (review). Int J Oncol 13, 993-1006.

Smith EA \& Macfarlane GT (1997) Dissimilatory amino acid metabolism in human colonic bacteria. Anaerobe $\mathbf{3}$, 327-337.

Smith JG, Youkoyama WH \& German JB (1998) Butyric acid from the diet: actions at the level of gene expression. Crit Rev Food Sci 38, 259-297.

Smith KM, Eaton AD, Finlayson LM \& Garside P (2000) Oral tolerance. Am J Respir Crit Care Med 162, S175-S178.

Solomons NW \& Rosenthal A (1985) Intestinal metabolism of a random-bonded polyglucose bulking agent in humans: in vitro and in vivo studies of hydrogen evolution. J Lab Clin Med $\mathbf{1 0 5}$, $585-592$.

Soontornchai S, Sirichakwal P, Puwastien P, Tontisirin K, Kruger D \& Grossklaus R (2003) Lactitol tolerance in healthy Thai adults. Eur J Nutr 38, 218-226.

Southon S, Livesey G, Gee JM \& Johnson IT (1985) Intestinal 
cellular proliferation and protein synthesis in zinc-deficient rats. Br J Nutr 53, 595-603.

Topping DL, Illman RJ \& Trimble RP (1985) Volatile fatty acid concentrations in rats fed diets containing gum arabic and cellulose separately and as a mixture. Nutr Rep Int 4, 809-814.
Watanabe M, Ozaki T, Hirata Y, Yamamoto O, Niida H, Ueda F, Yoshikuni Y \& Kimura K (1995) Mechanism for lowering blood ammonia levels by lactitol. Jpn J Pharmacol 67, 369-374.

Yoshioka M, Shimomura Y \& Suzuki M (1994) Dietary polydextrose affects the large intestine in rats. J Nutr 124, 539-547. 